\title{
Parametric Investigation of a Rail Damper Design Based on a Lab-Scaled Model
}

\author{
Alireza Jahan Tigh Kuchak ${ }^{1} \cdot$ Dragan Marinkovic ${ }^{1} \cdot$ Manfred Zehn $^{1}$
}

Received: 25 November 2019 / Revised: 9 March 2020 / Accepted: 9 April 2020

(c) The Author(s) 2020, corrected publication 2021

\begin{abstract}
Background Track noise is one of the main issues in the development of railway networks. It is well known that rail dampers, as a cost-effective, passive means of vibration reduction, do reduce the noise; still, neither the mechanism behind their action nor the influential parameters are well understood.

Purpose The main purpose of this work is to investigate the efficiency and influential parameters of a rail damper design based on a lab-scaled model of the rail-damper system and an accurate FE model.

Methods Based on experimental and numerical modal analyses and the Modal Assurance Criteria (MAC) analysis, the FE model updating technique was applied to develop a highly accurate FE model of the rail-damper system for the investigated frequency range. In a further step, the developed FE model is used in a parametric analysis to assess various damper parameters with respect to the efficiency of damping rail vibrations and, therewith, radiated noise.

Results The investigation performed based on FE simulations demonstrates how different material and geometric parameters of the damper influence the mobility decay rate of rail vertical vibrations. The investigated parameters are the thickness of still and rubber layers, stiffness and damping loss factor of rubber layers, and pre-force in the bolts that press the layers together. Conclusions It is shown that the FE model updating technique was capable of producing a highly accurate FE model despite the challenging properties of the real structure and that a combination of the lab-scaled model and the FE model represents a cost-effective approach.
\end{abstract}

Keywords Rail damper $\cdot$ FE analysis $\cdot$ Decay rate $\cdot$ Modal assurance criterion (MAC) $\cdot$ Eigenfrequencies $\cdot$ Eigenvectors

\section{Introduction}

Structural vibrations represent a rather important aspect in the lifetime of most load-carrying structures. In certain cases and by adding specific devices onto the structures, vibrations may even be used positively, such as for the purpose of energy harvesting [13,30], or damage detection $[18,31]$. However, the negative influence of structural vibrations is more frequently addressed as they may easily

Dragan Marinkovic

dragan.marinkovic@tu-berlin.de

Alireza Jahan Tigh Kuchak

alireza.jahantighkuchak@campus.tu-berlin.de

Manfred Zehn

manfred.zehn@tu-berlin.de

1 Department of Structural Analysis, Institute of Mechanics, Technical University Berlin, Str. d. 17. Juni 135, 10623 Berlin, Germany trigger damages and therewith compromise structural integrity. Beside those long-term consequences, there are also immediate negative consequences of vibrations, such as reduced ergonomics reflected in compromised comfort [6], unpleasant acoustic emissions [15], etc. Consequently, many research works were dedicated to this topic, ranging from proper description of structural damping [12] to development of various approaches for active $[4,11,20]$ and passive $[9,21]$ suppression of structural vibrations, with special focus to emitted noise attenuation [27] and vibration control.

In the past two decades, a number of studies related to noise reduction at the source of noise emission have been performed. One of the most effective, environment-friendly and economical noise reduction method used in rail tracks is the application of vibration absorber or rail damper. The rolling noise can be measured and predicted through combination of theoretically-developed models and field tests [17, $23,24]$. Both rail and wheel play a key role in this type of noise production, which is closely related to the combination 
of rail and wheel surface roughness [22]. There are several types of dampers that can be clamped or bolted onto the rail with the aim of reducing both vertical and lateral rail vibration $[2,5,10]$. This type of solution has proven reasonable and efficient [14]. Because of rail-wheel interaction and higher rail vibration amplitude in the vertical direction (bending), most of the studies are focused on suppressing the vertical amplitude. The achieved noise level reduction upon damper installation differs depending on the type of damper, material of rubber pads between rail and sleepers, dimensions and number of layers, etc.[1]. Noise reduction of up to $6 \mathrm{~dB}$ has been reported $[25,28]$.

A number of methods are available to measure and evaluate efficiency of a damper. A rather common and standardized method [3] is to measure the decay rate [19]. This method has been validated through field tests and, related to rails, it has been illustrated that the vibration amplitude decay rate is directly associated to the reduction of noise emitted from the rail [8]. To apply this method onto a track, i.e. as a field test, at least two complete measurements of rail vibration need to be done [16, 28]. The first one is performed prior to damper installation to determine vibrational behavior of the rail and the obtained result serves as a reference. Further measurements are done after the damper has been installed between sleepers on both sides of the rail. While the basic idea of the method is rather straightforward, which counts for one of its main advantages, it is also characterized by relatively high costs and a time-consuming process. The standard procedure requires a permission from authorities and involves demanding security issues. For each damper design, the measurements are repeated a sufficient number of times to filter out experimental errors. In addition, usually several damper designs are to be tested. Hence, it is easy to understand the extent of this aspect and why it represents a serious drawback. For that reason, there have been attempts to perform testing on scaled models (rails of $32 \mathrm{~m}$ and $6 \mathrm{~m}$ ) $[19,26]$.

The study presented here uses first a lab-scaled rail model in both experimental and numerical tests to build a sufficiently accurate FE model that is used in the next step to investigate the sensitivity of the rail's mobility decay rate on certain damper's parameters. The approach is supposed to enable cost-effective assessment and, furthermore, an improvement of the damper design.

\section{Methods}

\section{Lab-Scaled Model}

To make the experimental procedure less expensive and experiments feasible with the available equipment, one meter of UIC60 rail was selected as a scaled model. By means of four spring clamps, the rail was fitted with two rail dampers made by Schrey and Veit (S\&V) company (Fig. 1a, b). Embedding was done in the same manner as it is typically done onto a real track-the dampers were installed on both sides of the rail, exactly in the middle of the span (between the sleepers) to achieve the maximum effect onto the rail decay rate [10].

\section{Finite Element Model and Its Assessment}

In Fig. 2, the left side depicts the rail's 'I' profile, while the right-hand side of Fig. 2 shows the CAD model of one-meter UIC60 rail with the dampers. Table 1 gives the geometric and material properties of the rail. The tuned dampers from $\mathrm{S} \& \mathrm{~V}$ company consist of a damper platform and additional elastomer and steel layers, all of which are bolted together.

For proper analysis of the influence of various damper parameters onto the resulting decay rate, it was needed first to generate a suitable FE model of the rail-damper assembly, which is further to be used for the parametric analysis.

At first glance, building a suitable FE model of the raildamper assembly may appear a fairly simple task. However, the damper consists of a platform and a number of steel and rubber layers interconnected with bolts. It turned out that proper modeling of the interaction between the layers made of quite different types of materials is rather challenging. This is primarily due to the fact that the layers, which are pressed together by bolts, do not behave as totally fixed to each other over the boundary surface between the layers. Consequently, merging the FE nodes of the layers in contact would result in a too stiff FE model. Therefore, the contact conditions needed to be given special attention. Using the FE model updating technique based on experimental and

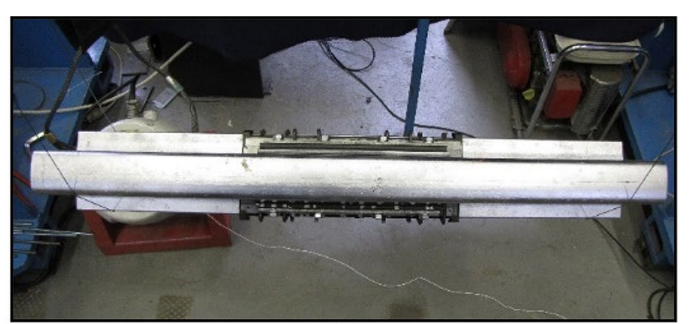

(a)

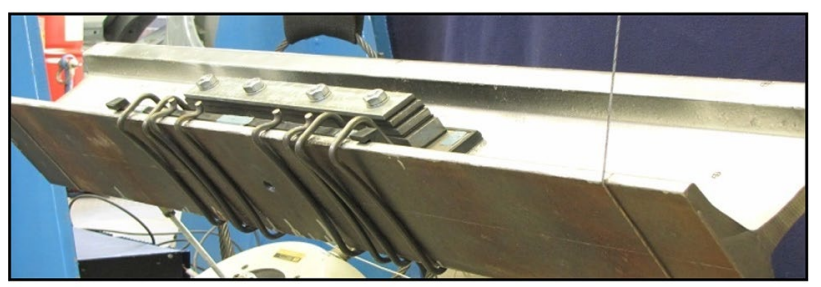

(b)

Fig. 1 a One-meter UIC60 rail fitted with two dampers in the middle, b spring claps used for embedding the dampers 
Fig. 2 CAD model of one-meter rail: a rail's 'I' cross section, b rail with dampers

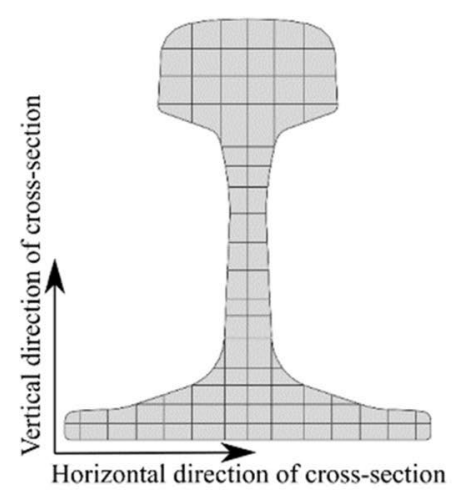

(a)

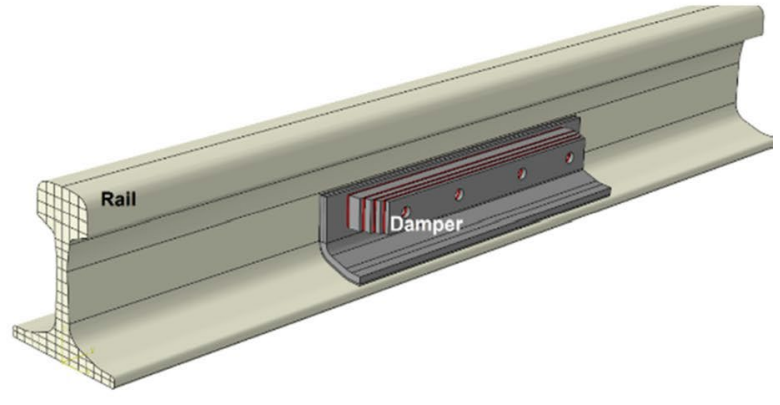

(b)
Table 1 The geometrical and material properties of the rail

\begin{tabular}{lll}
\hline Parameter & Notation & Value/info \\
\hline Young's modulus (MPa) & $E$ & $210 \times 10^{3}$ \\
Density $\left(\mathrm{t} / \mathrm{mm}^{3}\right)$ & $\rho$ & $7.8 \times 10^{-9}$ \\
Poisson' ratio & $v$ & 0.28 \\
Length $(\mathrm{m})$ & $L$ & 1 \\
Mass $(\mathrm{kg} / \mathrm{m})$ & $M$ & 60.34 \\
\hline
\end{tabular}

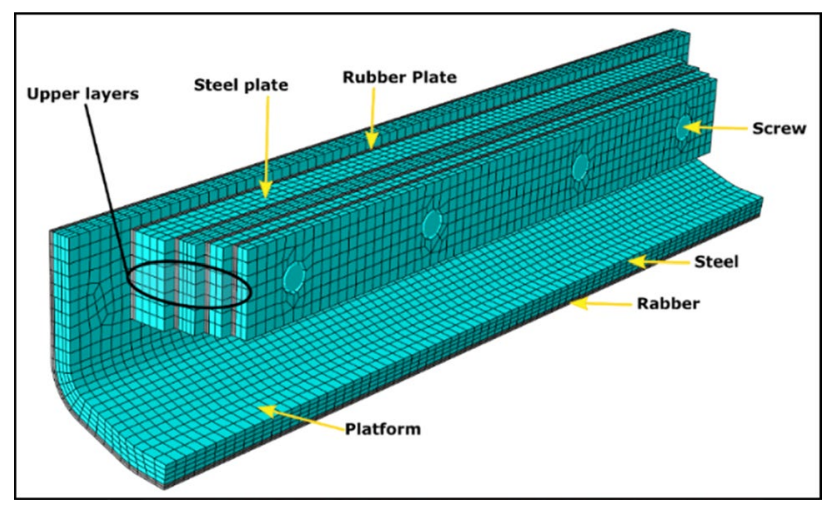

Fig. 3 FE model of rail damper: platform, steel and rubber layers, bolts

numerical modal analyses, the authors have successfully resolved this problem and generated an FE model of the damper (Fig. 3) that yields sufficiently high accuracy and can therefore be reliably used in further analyses [7].

The developed FE model of the rail damper is used here to build the FE model of the rail-damper assembly. It is worthwhile to give some basic information about the model. Due to the geometric properties of the rail and damper and the intended FE analyses, 3D solid elements were used in their discretization. To produce a regular and sufficiently fine FE mesh, the rail's 'I' cross-section was first adequately partitioned (Fig. 2a.), seeded and meshed.
This was followed by the bottom-up mesh technique. In this manner, automatic insertion of tetrahedron elements was avoided and the resulting 3D mesh of the rail contains the linear hexahedron elements (C3D8R element) only, thus improving the cost-effectiveness of the simulation. The damper was discretized using three different elements: linear solid (C3D8R), quadratic hybrid solid (C3D20H) and linear beam (B31) elements for the steel layers, rubbers layers and bolts, respectively. The quadratic hybrid solid element was applied for the rubber layers due to the nearly incompressible mechanical behavior of the material. As a result of the aforementioned FE model updating, the nodes of adjoining layers were merged only over a limited domain around the bolts.

The quality of the developed rail-damper FE model was tested by comparing the results of experimental and numerical modal analyses. To avoid the aspect of idealization of boundary conditions (typical for FE models), 'free-free' boundary conditions were set in the analyses performed. For realization of the boundary conditions in the experiment, the rail-damper assembly was suspended by a pair of thin strings. A shaker was used to produce excitation (Fig. 4a) and measurements were done by means of Laser Vibrometer PSV-400 (Fig. 4b). The Modal Assurance Criteria (MAC) values and comparison of experimentally and numerically obtained eigenfrequencies for the developed rail-damper FE model are given in Table 2 and Fig. 5a, b.

Using the built FE model, a parametric study is to be performed to determine the effects of different damper parameters on damping efficiency. The aim is to identify influential parameters and therewith propose a set of parameters that provide improved damping efficiency compared to the damper delivered by $\mathrm{S} \& \mathrm{~V}$ company for the purpose of tests. The FE model was scripted using programming language python to allow for fast and automatic change of the parameters, while Abaqus was used to perform the computations for each set of parameters. 
Fig. 4 Modal test of one-meter rail with damper: a the position of shaker, $\mathbf{b}$ the position and adjustment of vibrometer

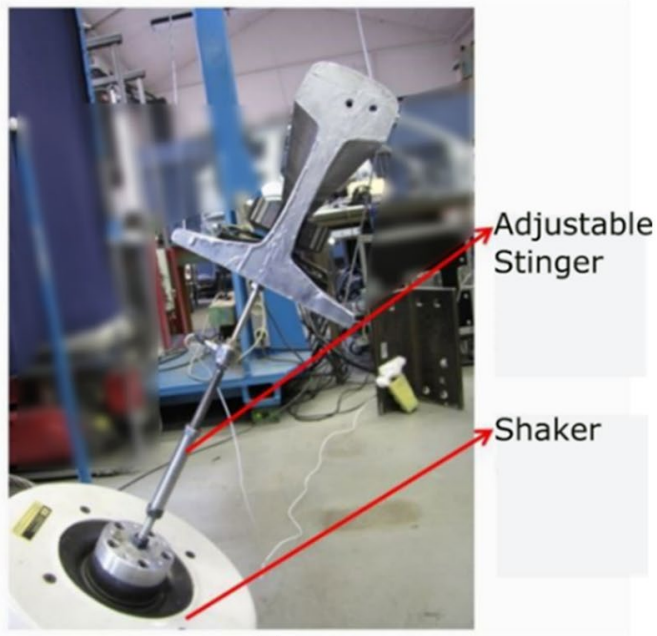

(a)

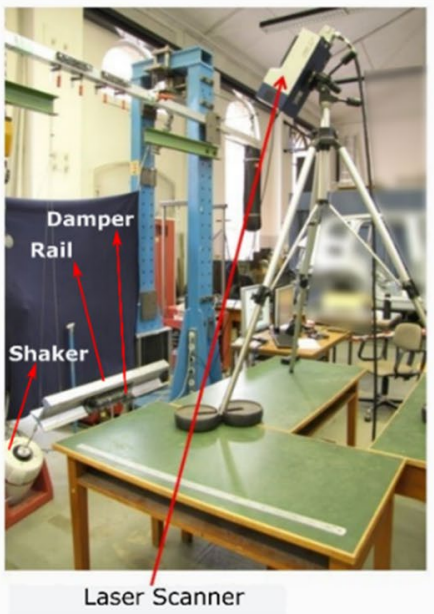

(b)
Table 2 The comparison of modal properties to validate the FE model

\begin{tabular}{llllcc}
\hline $\begin{array}{l}\text { Mode } \\
\text { number }\end{array}$ & Nature of modes & $\begin{array}{l}\text { Eigenfrequency } \\
\text { EXP. (Hz) }\end{array}$ & $\begin{array}{l}\text { Eigenfrequency } \\
\text { FEM (Hz) }\end{array}$ & $\begin{array}{l}\text { Relative } \\
\text { error (\%) }\end{array}$ & MAC (\%) \\
\hline 1 & 1st bending & 899.1 & 891.0 & 0.9 & 99.12 \\
2 & 2nd bending & 1853.4 & 1821.9 & 1.7 & 97.24 \\
3 & 3rd bending & 2483.8 & 2568.2 & -3.4 & 90.01 \\
4 & 1st torsion & 2946.3 & 2863.8 & 2.8 & 92.31 \\
5 & 4th bending & 3956.8 & 3972.6 & -0.4 & 83.22 \\
\hline
\end{tabular}

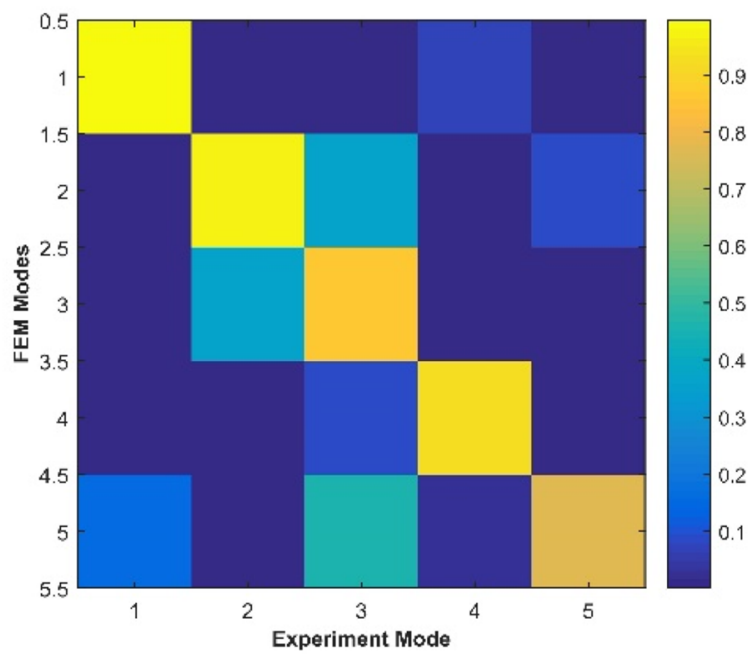

(a)

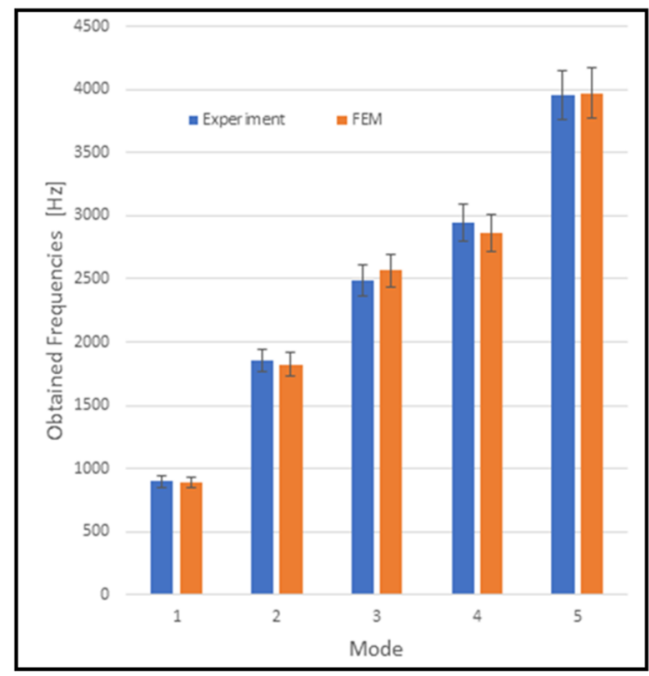

(b)

Fig. 5 a MAC values and $\mathbf{b}$ comparison of eigenfrequencies obtained upon updating the FE model 


\section{Parametric Study}

The mobility decay rate in the rail's vertical direction is used as the target variable to check the influence of the parameters. For an easier comparison, the results are computed in one-third octave frequency band. The rail decay rate is computed as proposed by Thompson et al. $[8,24,29]$ :

$\mathrm{DR} \approx \frac{4.343}{\sum_{n=0}^{n_{\max }} \frac{\left|A\left(x_{n}\right)\right|^{2}}{\left|A\left(x_{0}\right)\right|^{2}} \Delta x_{n}}$,

where $A$ represents the transfer mobility, $\Delta x_{n}$ is the interval distance between the points located at the half-distance

Table 3 Mechanical properties of steel and rubber layers in damper

\begin{tabular}{lll}
\hline & Notation & Value \\
\hline Steel layers & & \\
Young's modulus (MPa) & $E$ & $210 \times 10^{3}$ \\
Density (t/mm ${ }^{3}$ ) & $\rho$ & $7.8 \times 10^{-9}$ \\
Poisson' ratio & $v$ & 0.3 \\
Rubber layers & & \\
Young's modulus (MPa) & $E$ & 4.5 \\
Density (t/mm ${ }^{3}$ ) & $\rho$ & $1.2 \times 10^{-9}$ \\
Poisson' ratio & $v$ & 0.48 \\
\hline
\end{tabular}

between the measurment positions, $x_{n}$ is the set of $n$ measurement points, while $x_{0}$ is the excitation (shaker) position. In this work, for each central one-third octave frequency band up to $3200 \mathrm{~Hz}$, the decay rate is calculated to evaluate the effect of selected damper's parameters. The reference model is the one provided by $\mathrm{S} \& \mathrm{~V}$ company with the thickness of rubber layers equal to $2 \mathrm{~mm}$ and the thickness of the bootom steel layers of $15 \mathrm{~mm}$ and $8 \mathrm{~mm}$. The pre-force in each bolt is $2000 \mathrm{~N}$. The damping loss factor in rubber layers was specified by $\mathrm{S} \& \mathrm{~V}$ company as 0.2 . The basic material properties of the layers are given in Table 3 .

Chemical composition of the rubber can be modified relatively easily thus generating important mechanical properties in a fairly wide range. Hence, the parameters to be investigated are: (1) mechanical properties of the rubber, such as the Young's modulus and the damping loss factor, (2) geometrical variables, such as rubber and steel layers thickness, and finally, (3) the pre-force in bolts.

\section{Young's Modulus of the Rubber Layers}

The Young's modulus of the rubber is one of the mechanical parameters that can take values in a relatively wide range. In this study, it is changed within the range of 4-26 MPa with a step of $1 \mathrm{MPa}$ in the range 4-10 MPa and a step of $2 \mathrm{MPa}$ in the range 10-26 MPa. Figure 6 reveals the influence of the rubber Young's modulus for each third-octave

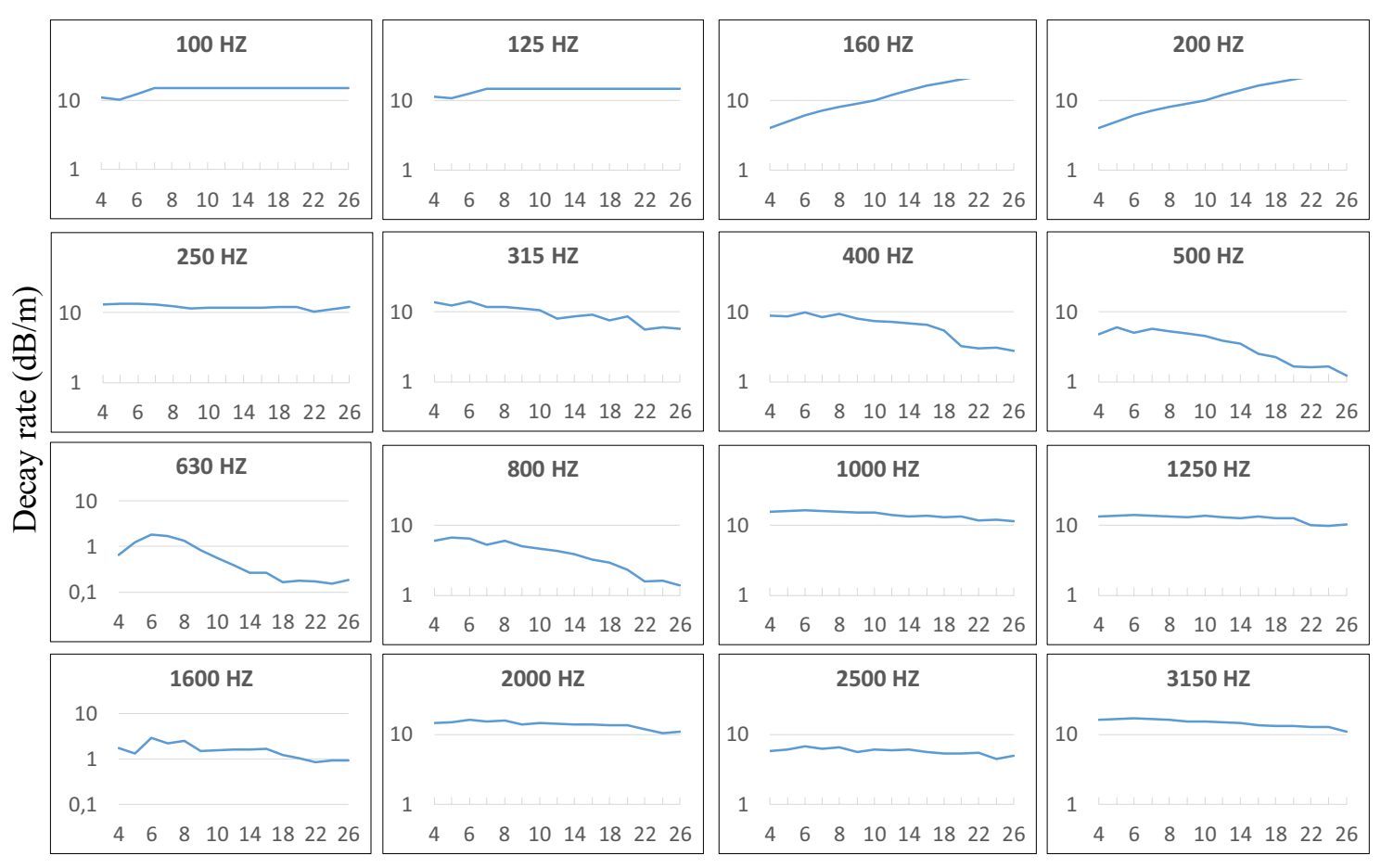

Young's Modulus (MPa)

Fig. 6 Decay rate versus Young's modulus for each one-third octave frequency 
frequency separately. Interestingly, with the increasing rubber's Young's modulus, various effects are observed at different frequencies-at certain frequencies a relatively small change is observed, but the mobility decay rate may also significantly increase or decrease at other frequencies. Assuming the same importance of each observed frequency (i.e. the same 'weight factor'), the Young's modulus of $7 \mathrm{MPa}$ is selected as a preferable one based on the obtained results.

\section{Thickness of Rubber Layers}

The considered damper includes eight layers assembled onto the platform. Four of those layers are made of rubber and it is assumed that they all have the same thickness. The thickness of the rubber layers is selected as one of the parameters to study its influence onto the mobility decay rate by varying it from 1 to $20 \mathrm{~mm}$ with the step size of $0.5 \mathrm{~mm}$. Figure 7 shows the influence of this parameter at all the considered frequencies. It is mainly the dependency of the mobility decay rate on this parameter at higher frequencies (above $500 \mathrm{~Hz}$ ) that makes the thickness of $10 \mathrm{~mm}$ the preferable value.

\section{Damping Loss Factor of Rubber Layers}

Another material parameter of the rubber that can be modified by changing the chemical composition of the rubber, technological processing, etc., is the damping loss factor. In this study, the value of this parameter varies in the range of $0.1-1.3$ with the step size of 0.05 . Figure 8 shows that the effect of this parameter is diverse as it can both increase and decrease the decay rate depending on the investigated frequency. The influence of this parameter is relatively small at most of the frequencies. Based on the performed calculations, the damping loss factor of 0.45 is suggested.

\section{Pre-force Variation in the Bolts}

Bolted connections are inexpensive, easy to assemble and offer the possibility of tuning the pre-force in the connected layers. Hence, the pre-force in the range of $0-9$ $\mathrm{kN}$ with the step size of $0.5 \mathrm{kN}$ is investigated here. It is assumed that all bolts are tightened so as to produce the same pre-force. Figure 9 reveals that this parameter has somewhat more complex influence on the obtained results. Changing the pre-force in the predefined range may have diverse influence even if the observation is limited to only one frequency. In addition, at only a few of the observed frequencies, the influence is small. Again, weighting equally the importance of all frequencies, the pre-force of $3 \mathrm{kN}$ is the preferable one for the considered damper.

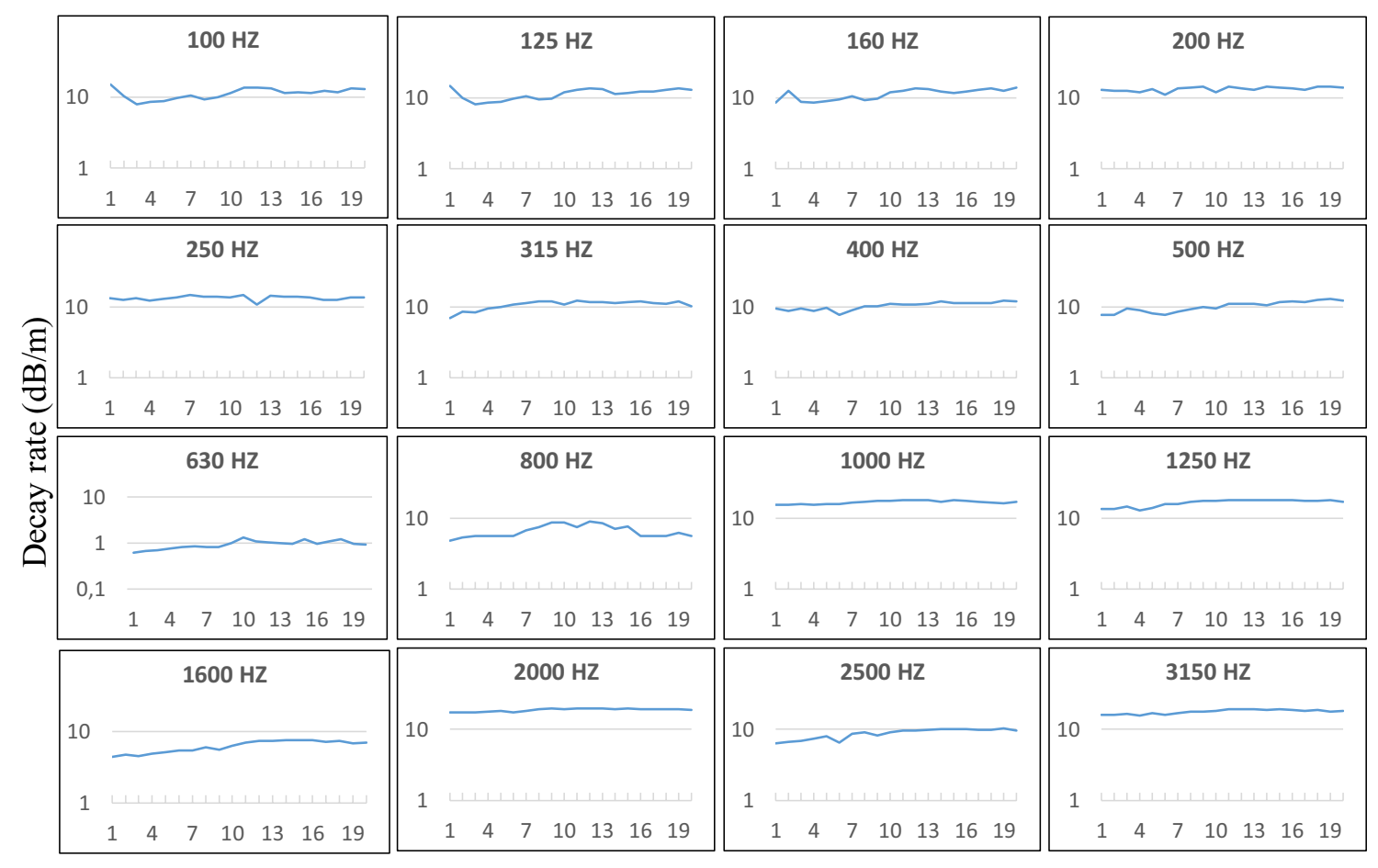

Rubber thickness (mm)

Fig. 7 Decay rate versus rubber thickness for each one-third octave frequency 


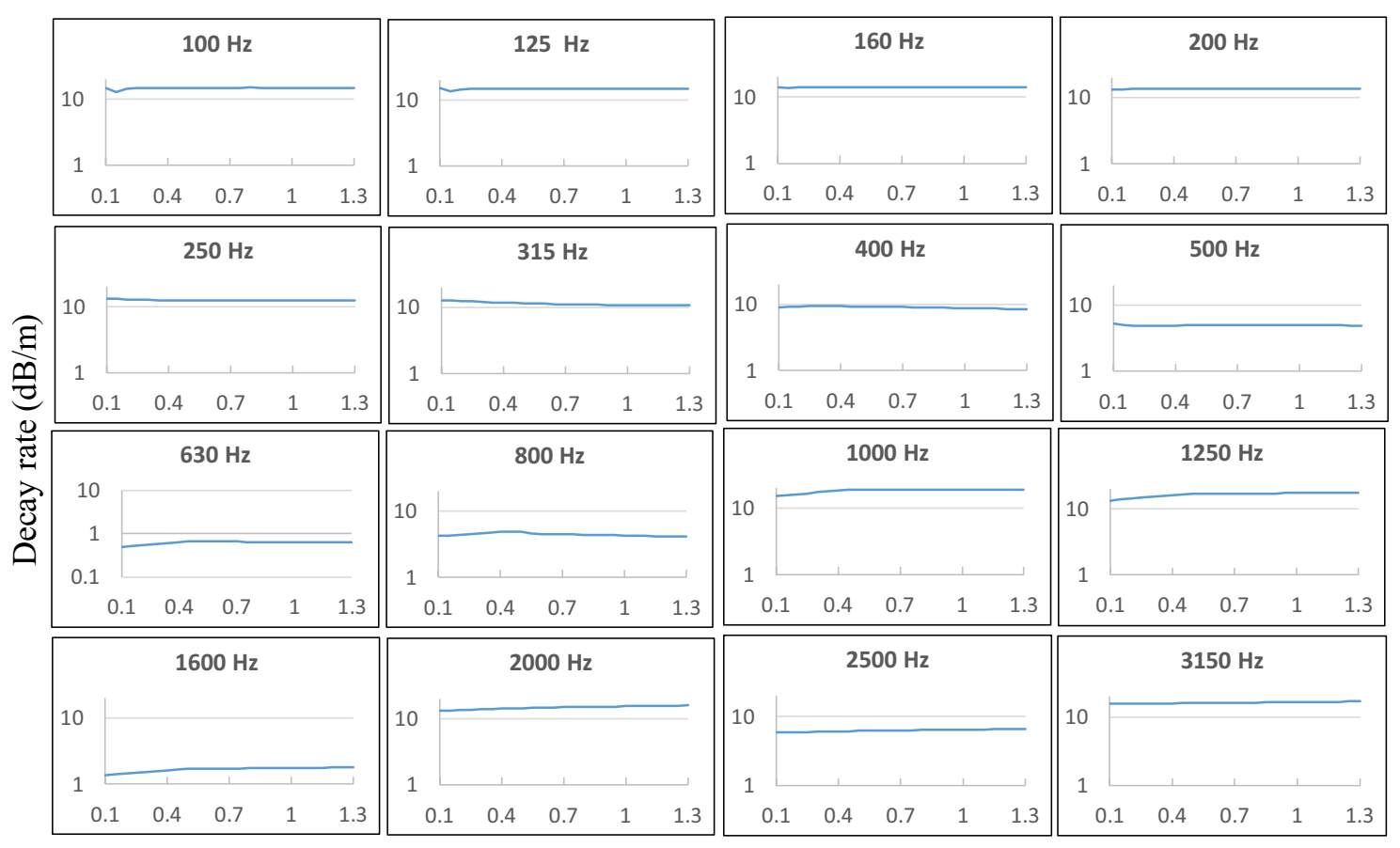

Damping loss factor

Fig. 8 Decay rate versus damping loss factor for each one-third octave frequency

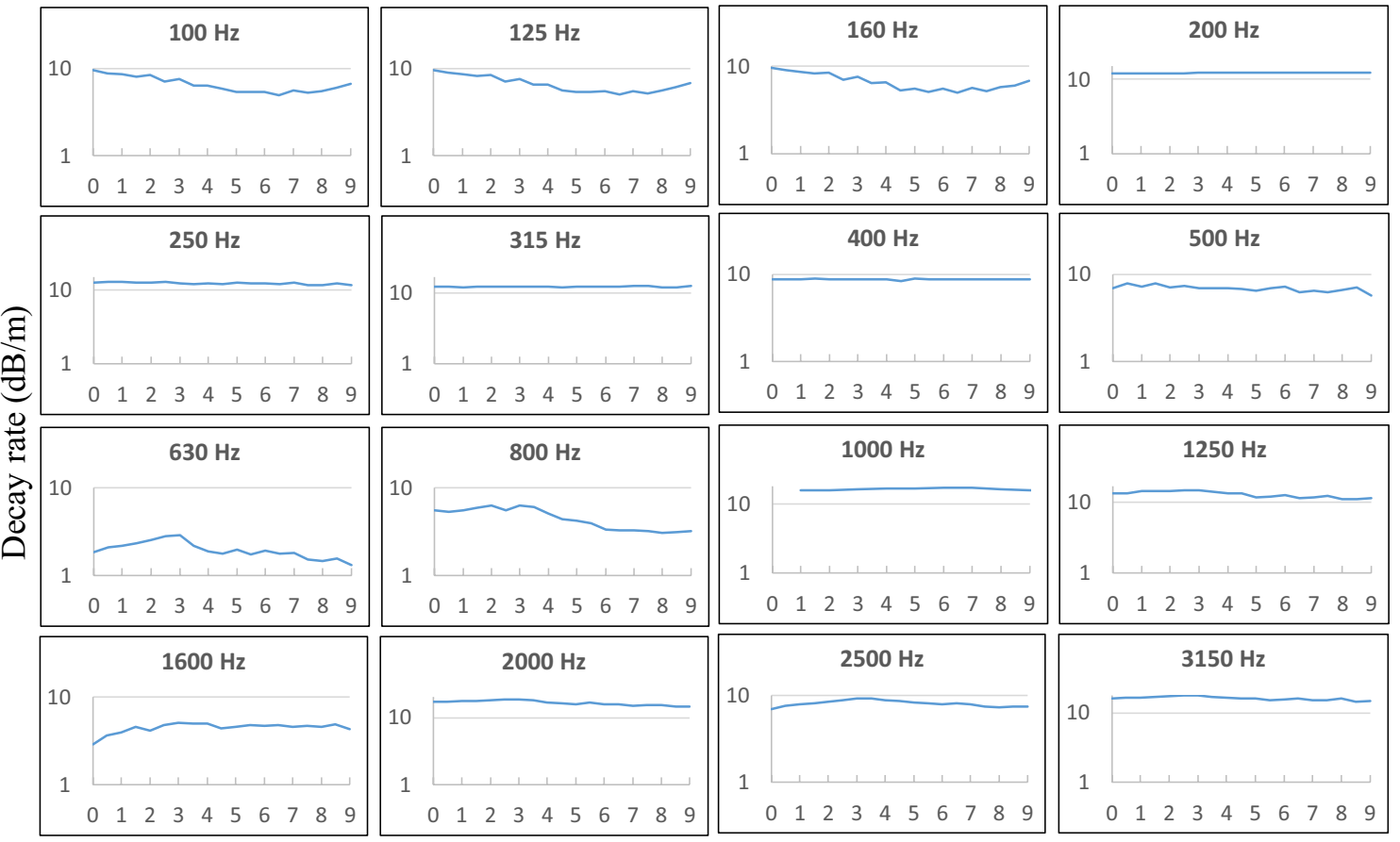

Pre-force $(\mathrm{KN})$

Fig. 9 Decay rate versus pre-force for each one-third octave frequency 


\section{Thickness of Steel Layers}

Besides the four rubber layers, the upper layers that are assembled onto the platform include also four steel layers. Their thickness is also a parameter worth of investigation. While the thickness of all rubber layers was assumed same and then changed within the predefined range, only the thickness of the two bottom steel layers is investigated here. As those layers have different thicknesses in the model provided by the $\mathrm{S} \& \mathrm{~V}$ company $(15 \mathrm{~mm}$ and $8 \mathrm{~mm})$, 'added thickness' $(\Delta t)$ is selected as a parameter and applied to the steel layers. This actually implies that the thickness of the two bottom steel layers is changed simultaneously by adding $\Delta t$ to it, with $\Delta t$ in the range between -4 and $+4 \mathrm{~mm}$ and an increment of $1 \mathrm{~mm}$. The minus sign means that the thickness is reduced, while the plus sign indicates an increase in thickness. Figure 10 shows how this change influences the decay rate. Interestingly, while the influence at lower frequencies is practically negligible, the decay rate at higher frequencies increases with the increasing thickness of the steel layers. Finally, a $4 \mathrm{~mm}$ increase in thickness of the two steel layers is selected as a preferable value.

\section{Discussion}

To summarize the above results and identify which frequencies are particularly affected and which parameters are more influential, the above results are presented here in another form. Namely, the decay rate computed for the initial model (parameters as in the model provided by the $\mathrm{S} \& \mathrm{~V}$ company; introduction to "Parametric study") is compared to the decay rates obtained with five other FE models, in each of which one of the parameters is set to have the preferable value (determined above), while all other parameters are kept at their initial values. The relative increase of the decay rate at each one-third octave frequency for those five FE models is presented on the 3D diagram in Fig. 11.

The significant increase of decay rate is observed at frequencies above $500 \mathrm{~Hz}$. The frequency range of $630-2000 \mathrm{~Hz}$ is of particular interest for the railway related acoustics. Therefore, the results for all the frequencies above and including $630 \mathrm{~Hz}$ are given again in a simpler diagram in Fig. 12.

From the results, it is obvious that the preferable thickness of rubber layers significantly increases the decay rate at all frequencies compared to the initial value of this parameter. On the other hand, all other parameters exhibit mixed influence, more significant at some frequencies, and less significant at others. The damping loss factor of

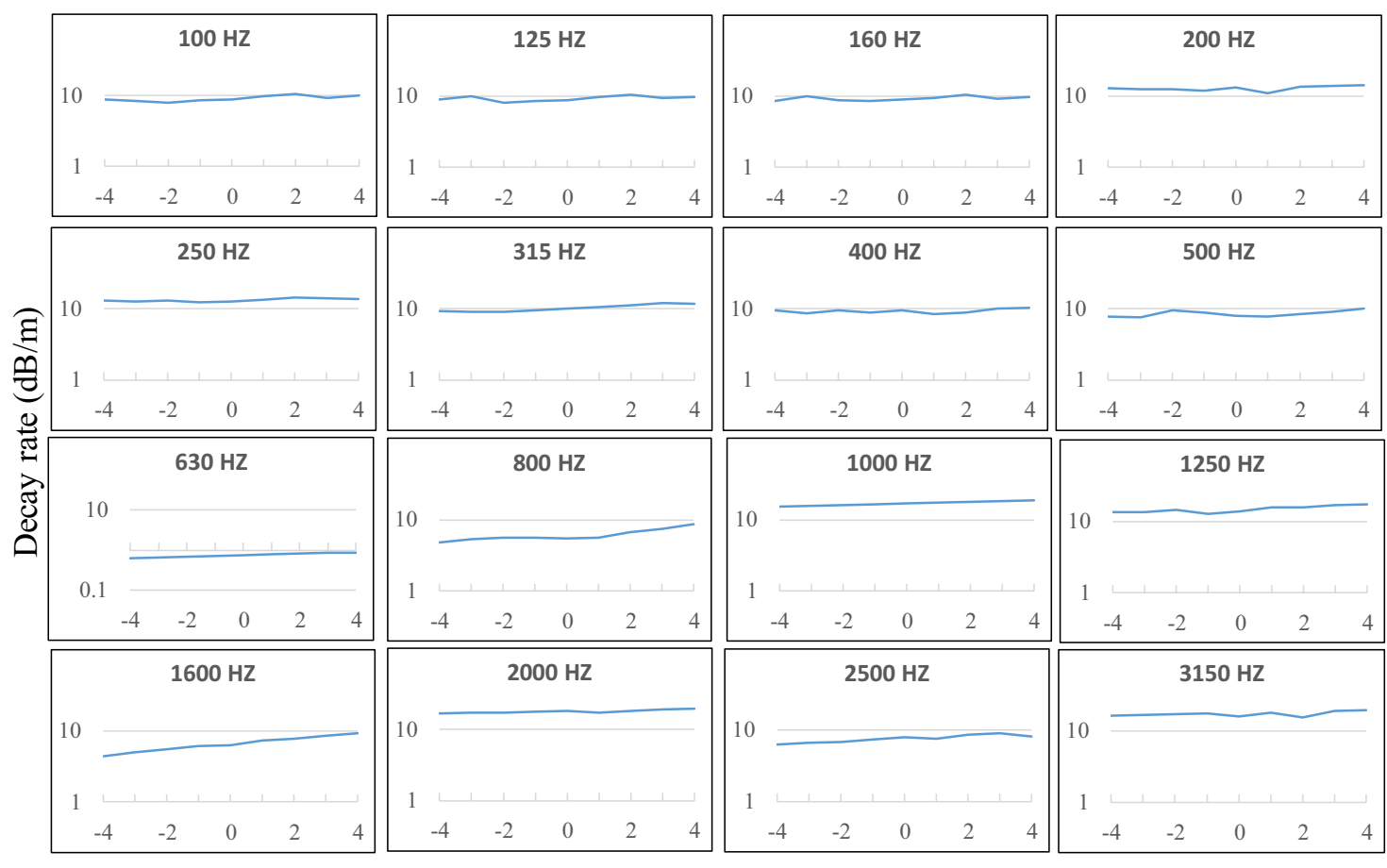

Steel added thickness $(\mathrm{mm})$

Fig. 10 Decay rate versus added steel thickness for each one-third octave frequency 
Fig. 11 Relative increase of decay rate for each investigated parameter compared to the initial model

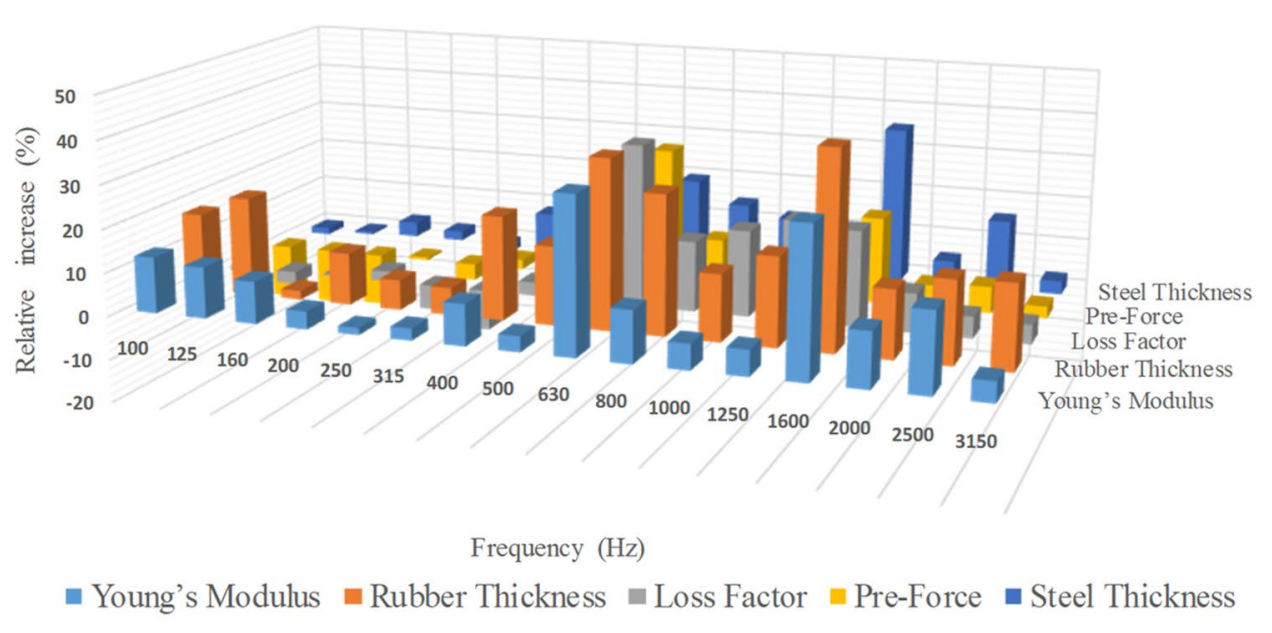

Fig. 12 Relative increase of decay rate for investigated parameters at frequencies above $630 \mathrm{~Hz}$

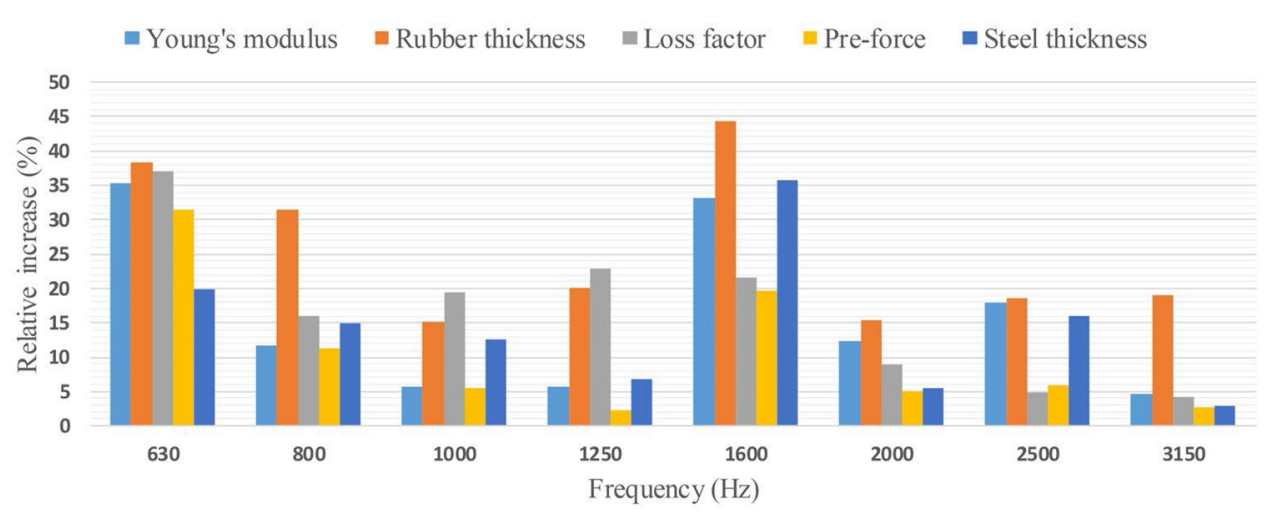

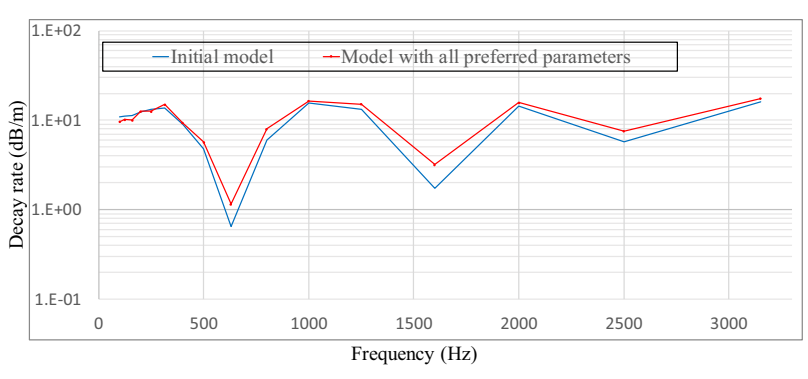

Fig. 13 Decay rates for the initial and FE model with preferable damper parameters

rubber layers and the thickness of the steel layers demonstrated important influence at several frequencies. It is reasonable to assume that the importance of various parameters at different frequencies strongly depends on the vibration modes of the rail-damper assembly.

Finally, a FE model with all preferable damper parameters is generated for the purpose of comparison with the initial mode. The resulting decay rates obtained by means of FE simulations in the observed frequency range are presented in Fig. 13.

\section{Conclusions}

The paper elaborates the idea of testing and improving rail damper efficiency based on a lab-scaled rail model with the length of $1 \mathrm{~m}$. Such an approach makes both experimental testing and numerical simulations less expensive, more efficient and feasible with limited equipment. In the first step, a physical model was used to set up a sufficiently accurate FE model of the rail-damper assembly by means of FE model updating technique. The presence of layers made of materials with remarkably different properties, in this case steel and rubber, and their interaction in the assembly added complexity to modeling. Experimental and numerical modal analyses were performed as basis for model updating. Furthermore, the resulting FE model was used in combination with scripting to perform a parametric study. Mobility decay rate of rail vertical vibrations was used as a parameter representative of radiated noise reduction. The objectives of the parametric study were to identify influential parameters with respect to railway acoustics and determine their preferable values. In this manner, a successful and cost-effective approach to damper improvement was demonstrated. The objective 
of the further work is to apply the approach to large scale models. This is already a work in progress.

Funding Open Access funding enabled and organized by Projekt DEAL.

Open Access This article is licensed under a Creative Commons Attribution 4.0 International License, which permits use, sharing, adaptation, distribution and reproduction in any medium or format, as long as you give appropriate credit to the original author(s) and the source, provide a link to the Creative Commons licence, and indicate if changes were made. The images or other third party material in this article are included in the article's Creative Commons licence, unless indicated otherwise in a credit line to the material. If material is not included in the article's Creative Commons licence and your intended use is not permitted by statutory regulation or exceeds the permitted use, you will need to obtain permission directly from the copyright holder. To view a copy of this licence, visit http://creativecommons.org/licenses/by/4.0/.

\section{References}

1. Asmussen B, Stiebel D, Kitson P, Farrington D, Benton D (2008) Reducing the noise emission by increasing the damping of the rail: results of a field test. In: Noise and vibration mitigation for rail transportation systems, pp 229-235

2. Dool V, Philip H (2007) Rail dampers, rail infrastructure gets quiet. INTER-NOISE and NOISE-CON Congress and Conference Proceedings 2007(5):2312-2320

3. EN15461:2008 (2008) Railway applications-noise emissions, characterization of the dynamic properties of track sections for pass by noise measurements

4. Gabbert U, Duvigneau F, Ringwelski S (2017) Noise control of vehicle drive systems. Facta Univ Ser Mech Eng 15(2):183-200

5. Ho W, Wong B, Tam P-L, Cai T (2015) Rail damper optimization using FEA. In: Proceedings of the 22nd International Congress on Sound andVibration (ICSV 22), Florence, Italy, pp 4831-4838

6. Huang Y (2019) Subjective discomfort model of the micro commercial vehicle vibration over different road conditions. Appl Acoust 145:385-392

7. Jahan Tigh Kuchak A, Marinkovic D, Zehn M (2020) Finite element model updating: case study of a rail damper. Struct Eng Mech 73(1):27-35

8. Jones CJC, Thompson DJ, Diehl RJ (2006) The use of decay rates to analyse the performance of railway track in rolling noise generation. J Sound Vib 293(3-5):485-495

9. Khatake P, Nitnaware PT (2013) Vibration mitigation using passive damper in machining. Int J Mod Eng Res 3(6):3649-3652

10. Maes J, Sol H (2003) A double tuned rail damper - Increased damping at the two first pinned-pinned frequencies. J Sound Vib 267(3):721-737

11. Marinković D, Nestorović T, Marinković Z, Trajkov M (2012) Modelling and simulation of piezoelectric adaptive structures. Trans Famena 36(1):25-34

12. Mitrev R, Savov S (2017) A theoretical-experimental approach for elasto-damping parameters estimation of cone inertial crusher mounting. Facta Univ Ser Mech Eng 15(1):73-83

13. Noll M, Lentz L, Von Wagner U (2019) On the discretization of a bistable cantilever beam with application to energy harvesting. Facta Univ Ser Mech Eng 17(2):125-139
14. Oertli J (2003) The STAIRRS project, work package 1: a costeffectiveness analysis of railway noise reduction on a European scale. J Sound Vib 267(3):431-437

15. Otto J, Ostermeyer G (2019) High-frequency vibrations in the contact of brake systems. Facta Univ Ser Mech Eng 17(2):103-112

16. Parker A, Weber C (2010) Rail dampers: the first Australian field trial. In: Proceedings of 20th international congress on acoustics, pp 23-27

17. Remington PJ (1976) Wheel/rail noise-Part IV: Rolling noise. J Sound Vib 46(3):419-436

18. Saravanakumar K, Lakshminarayanan BS, Arumugam V, Santulli C, Pavlovic A, Fragassa C (2019) Quasi-static indentation behavior of GFRP with milled glass fiber filler monitored by acoustic emission. Facta Univ Ser Mech Eng 17(3):425-443

19. Squicciarini G, Toward MGR, Thompson DJ (2015) Experimental procedures for testing the performance of rail dampers. J Sound Vib 359:21-39

20. Talib E, Shin J, Kwak MK (2019) Designing multi-input multioutput modal-space negative acceleration feedback control for vibration suppression of structures using active mass dampers. J Sound Vib 439:77-98

21. Tan J, Michael Ho S, Zhang P, Jiang J (2019) Experimental study on vibration control of suspended piping system by single-sided pounding tuned mass damper. Appl Sci 9(2):1

22. Thompson DJ (2008) Railway noise and vibration: mechanisms, modelling and means of control. Elsevier, New York

23. Thompson DJ, Fodiman P, Mahé H (1996) Experimental validation of the twins prediction program for rolling noise, Part 2: Results. J Sound Vib 193(1):137-147

24. Thompson DJ, Hemsworth B, Vincent N (1996) Experimental validation of the twins prediction program for rolling noise, part 1: description of the model and method. J Sound Vib 193(1):123-135

25. Thompson DJ, Jones CJC, Waters TP, Farrington D (2007) A tuned damping device for reducing noise from railway track. Appl Acoust 68(1):43-57

26. Toward M, Thompson DJ (2012) Laboratory methods for testing the performance of acoustic rail dampers. In: Proceedings of the Acoustics 2012, April 2012, Nantes, France, hal-00810837f

27. Valvano S, Orlando C, Alaimo A (2019) Design of a noise reduction passive control system based on viscoelastic multilayered plate using PDSO. Mech Syst Signal Process 123:153-173

28. Van Haaren E, van Keulen GA (2008) New rail dampers at the railway link roosendaal-vlissingen tested within the dutch innovation program. In: Noise and vibration mitigation for rail transportation systems. Springer, pp 378-383

29. Vincent N, Thompson DJ (1995) Track dynamic behaviour at high frequencies. Part 2: experimental results and comparisons with theory. Vehicle Syst Dyn 24(1):100-114

30. Wei C, Jing X (2017) A comprehensive review on vibration energy harvesting: modelling and realization. Renew Sustain Energy Rev 74:1-18

31. Yan YJ, Cheng L, Wu ZY, Yam LH (2007) Development in vibration-based structural damage detection technique. Mech Syst Signal Process 21(5):2198-2211

Publisher's Note Springer Nature remains neutral with regard to jurisdictional claims in published maps and institutional affiliations. 